Cahiers $d u$ MONDE RUSSE

\section{Cahiers du monde russe}

Russie - Empire russe - Union soviétique et États indépendants

$56 / 4 \mid 2015$

Médiateurs d'empire en Asie centrale (1820-1928)

\title{
Andrea Graziosi (textes réunis et présentés par), avec la collaboration d'Iryna Dmytrychyn, Lettres de Kharkov, La famine en Ukraine 1932-1933
}

Lucien Bianco

\section{OpenEdition}

Édition électronique

URL : http://journals.openedition.org/monderusse/8260

DOI : $10.4000 /$ monderusse. 8260

ISSN : $1777-5388$

Éditeur

Éditions de l'EHESS

Édition imprimée

Date de publication : 1 octobre 2015

Pagination : 865-868

ISBN : 978-2-7132-2507-9

ISSN : $1252-6576$

Référence électronique

Lucien Bianco, «Andrea Graziosi (textes réunis et présentés par), avec la collaboration d'Iryna Dmytrychyn, Lettres de Kharkov, La famine en Ukraine 1932-1933 », Cahiers du monde russe [En ligne] 56/4 | 2015, mis en ligne le 16 mars 2016, Consulté le 25 septembre 2020. URL : http:// journals.openedition.org/monderusse/8260 ; DOI : https://doi.org/10.4000/monderusse.8260

Ce document a été généré automatiquement le 25 septembre 2020. 


\section{Andrea Graziosi (textes réunis et présentés par), avec la collaboration d'Iryna Dmytrychyn, Lettres de Kharkov, La famine en Ukraine 1932-1933}

\section{Lucien Bianco}

\section{RÉFÉRENCE}

Andrea GRAZIOSI (textes réunis et présentés par), avec la collaboration d'Iryna Dmytrychyn, Lettres de Kharkov, La famine en Ukraine 1932-1933, Paris : Les éditions Noir sur Blanc, 2013, 280 p.

1 Les Cahiers du Monde russe avaient eu, voici un quart de siècle, la primeur de ces documents découverts en 1987 par Andrea Graziosi dans les archives du ministère des Affaires étrangères d'Italie ${ }^{1}$. Le choix des documents initialement publiés favorisait l'acmé de la famine ukrainienne : les dépêches de 1933 s'y trouvaient déjà quasiment au complet (il en manquait une seule sur 25). La nouvelle édition ajoute cinq dépêches de 1932, cinq de 1934 (concernant en particulier la répression-prévention des manifestations du nationalisme ukrainien) et les sept dépêches de 1930. Chacune de ces dernières sauf une, consacrée à l'épidémie de typhus en Ukraine, relate des cas de résistance à la collectivisation. Antérieures à la famine, ces dépêches initiales éclairent donc ses causes, les suivantes son déroulement.

Qu'est-ce que la présente édition apporte de neuf par rapport à celle de 1989 ? D'une part, le passage de 38 à 56 dépêches. Parmi les nouvelles, retenons en particulier celles : 
3 - du 18 février 1932, qui transmet l'appel désespéré de paysans inconnus au consulat général de Pologne : « Nous autres Russes sommes décidés à nous adresser à vous, gens d'autres pays, pour vous demander de l'aide ";

4 - du 25 juillet 1932, relative à la fameuse conférence du PC ukrainien des 6 au 9 juillet en présence de Molotov et Kaganovič ;

5 - du 6 janvier 1933 : « Des dirigeants ukrainiens dans l'industrie et l'administration ont dit de Staline dans la nuit du Nouvel An : "Le fanatique est devenu fou" »(p.150);

6 - enfin les dépêches de $1934\left(n^{\circ} 51,52,54\right)$ relatives au nationalisme ukrainien et surtout à la répression qui le frappe.

7 L'autre apport nouveau réside dans l'introduction d'Andrea Graziosi, beaucoup plus étoffée que celle de 1989. La présentation de la politique fasciste à l'égard de l'URSS et des diplomates en poste en URSS au début des années 1930 était incluse dans l'édition de 1989. Elle est désormais suivie d'une interprétation substantielle des famines soviétiques de 1931-1933, à la lueur de tout ce que l'on a appris depuis 1991. Elle insiste à juste titre sur le tournant fatidique de l'automne 1932 et la spécificité de la famine ukrainienne, énormément aggravée par les décisions politiques qu'inspire à Stalin la crainte du séparatisme ukrainien. Autre contribution nouvelle : la préface de Nicolas Werth, qui résume très bien en peu de mots l'immense intérêt de dépêches « au ton mesuré, factuel et analytique ".

8 À l'instar du préfacier et du présentateur, je suis impressionné par la rigueur, l'objectivité et même la "sympathie humaniste»(p.20) dont font preuve ces serviteurs d'un État fasciste (les deux ambassadeurs successifs seront plus tard démis pour désaccord avec la politique étrangère du régime). Une dépêche ( $\mathrm{n}^{\circ} 33 \mathrm{du} 31$ mai 1933) a néanmoins une tonalité antisémite. Elle est due à l'auteur des documents les plus nombreux et les mieux informés : Sergio Gradenigo, consul d'Italie à Har'kov. Les villes ukrainiennes comptaient alors moins d'Ukrainiens que de Juifs et de Russes en majorité antisémites, dont le consul a peut-être épousé ou partagé les préjugés : c'est, rappelle Andrea Graziosi (p. 21), à Kiev qu'avait été rédigé le « Protocole des Sages de Sion ». Plus aisément pardonnables sont de rares estimations exagérées du nombre de morts de faim sur la base des rumeurs qui circulaient alors : souvenons-nous que Robert Conquest lui-même a avancé des chiffres trop élevés. Pour le reste, cette publication confirme que des témoins peuvent fort bien révéler et analyser ce que les générations successives s'obstineront à ignorer. Mussolini était beaucoup mieux informé (il a griffonné mainte dépêche au crayon bleu) de la famine ukrainienne que les dirigeants des démocraties occidentales : rappelons-nous Herriot ! Mieux aussi que la quasi-totalité des historiens pendant un bon demi-siècle : jusqu'à Mace et Conquest précisément $^{2}$. De Har'kov surtout, puis de Kiev, mais aussi de postes consulaires riverains de la mer Noire (Novorossijsk, Batum) et de Moscou, ses diplomates l'informaient de la tragédie au fur et à mesure de son déroulement. À part les sept premières dépêches du recueil, antérieures à une famine dont elles éclairent les causes, et les sept dernières, pour une bonne part consacrées à la répression/prévention du nationalisme ukrainien en 1934, toutes datent de 1932-1933: 42 sur 56 dépêches. Elles permettent de suivre de mois en mois la progression de la famine, depuis ses débuts au printemps 1932 jusqu'au sinistre sommet du printemps 1933. Le tournant de l'automne 1932 est aussitôt pressenti par ces observateurs perspicaces. 
9 Les divers aspects de la catastrophe, tels qu'on les a identifiés depuis peu, ressortissent avec netteté de l'état des lieux dressé par ses contemporains. En premier lieu l'implacable lutte pour le blé qui oppose l'État aux paysans redevenus des serfs, l'inscription sur la " liste noire » de ceux (foyers ou villages) qui n'ont pas « rempli le plan de collecte " et ne peuvent désormais acheter le moindre produit à la coopérative locale ; la "pédagogie infernale ", pour reprendre l'expression d'Annie Kriegel, qui vise à changer le " matériel ethnographique » (p. 180), à inculquer à ces ruraux obtus l'élémentaire vérité : « qui ne travaille pas (autrement dit, qui n'adhère pas au kolkhoze ou sabote le travail collectif) ne mange pas "; le refus de toute aide aux affamés, empêchés de fuir ; ceux qui sont néanmoins parvenus en ville, la police en ramasse deux mille par jour à Har'kov en juillet 1933 et les jette dans des ravins, à quatre heures de la gare la plus proche (p. 205-06) ; les morts ou les moribonds, on les décharge dans des fossés ou on les enterre vivants. Un « camion des morts " embarque une fillette, que sa mère avait envoyée faire la queue pour le pain et qui lisait assise sur le trottoir en attendant son tour : " inutile de s'égosiller et de crier que sa maison est là, à côté ". La mère prévenue se précipite au poste de police le plus proche, on la chasse. Grâce à une amie employée à la GPU, elle réussit enfin à retrouver sa fille parmi les vivants et les morts sans joue - étaient-ce des rats pendant la nuit ou des affamés pendant le jour ? »(p. 194-195).

10 En deuxième lieu, la résistance paysanne, mentionnée dans chacune des six premières dépêches (datées de février à avril 1930) contemporaines de la collectivisation. Face à une répression sans merci, la résistance prend des formes plus passives mais néanmoins efficaces. Elles sont admirablement analysées, comme le souligne Nicolas Werth dans la préface, par Leone Sircana, vice-consul d'Italie à Novorossijsk (dépêche du 8 avril 1933, p. 8-9 et 169) :

L'appareil soviétique excessivement armé et puissant se trouve dans l'impossibilité de chercher la solution et la victoire dans une ou plusieurs batailles rangées ; l'ennemi n'est pas massé, il est dispersé, la bataille cherchée est provoquée en vain et on s'épuise en une série sans fin de très petites, ou plutôt de minuscules opérations : ici un champ n'est pas sarclé, là quelques quintaux de blé sont cachés ; sans compter un tracteur inopérant, un deuxième volontairement détraqué, un troisième en vadrouille au lieu de travailler ; ou bien encore des kolkhozes ou des villages qui ne sèment pas, d'autres qui ont mangé les semences ou les ont vendues en fraude ou bien ils ont abattu les bêtes de somme ; et de constater ensuite qu'un entrepôt a été dévalisé, que les livres de comptes, petits ou grands, sont mal tenus ou falsifiés [...] Et ainsi de suite, à l'infini, et toujours à nouveau dans cet immense territoire ! [...] On ne réussit pas plus à trouver un ennemi compact, à l'écraser dans une action de grande envergure et à régler ainsi la question. Même dans ce cas, l'ennemi, il faut aller le chercher maison par maison, village par village.

11 Ailleurs aussi, le blé pousse sur du blé non récolté, les camions du kolkhoze sont réduits à un tas de ferraille, des villageois massacrent militants et dirigeants communistes. À Seržak, « le fils du Président du comité exécutif du PC a été enlevé, dépecé et les morceaux ont été jetés devant la maison de son père. Dans ce même Seržak, la maison d'un dirigeant communiste a été arrosée de pétrole et incendiée » (Har'kov, 24 février 1933).

12 En troisième lieu, la description anthropologique de l'humanité confrontée à la famine. À force d'ingurgiter un " pain " à base d'écorce de bouleau et de lichen, ailleurs un pain qui contient du bois, de la paille hachée, un épi entier et de la ficelle (Moscou, $1^{\mathrm{er}}$ novembre 1932 et 20 mars 1933), on s'expose à la péritonite, à la malaria, au typhus : 
on en recense près de trois cents nouveaux cas par jour à Har'kov au début de décembre 1933 (p. 240). Des parents abandonnent leurs enfants en ville, en se raccrochant à l'espoir qu'une bonne âme les recueillera, et s'en retournent mourir au village. Parfois compatissants, les citadins sont en règle générale hostiles aux paysans, qu'ils chassent ou signalent à la police (p. 205). Les paysans le leur rendent bien, qui mettent le feu aux maisons où sont logés les travailleurs citadins envoyés aux champs afin de suppléer la main-d'œuvre paysanne décimée par la famine, tuant des dizaines d'entre eux dans un village situé entre Kiev et la frontière polonaise (p. 219). Violences, lynchages de voleurs ou d'innocents, infanticides sévissent partout. Certains parents tuent leurs enfants et les mangent, d'autres assassinent voisins et passants trop faibles pour se défendre, puis consomment ou vendent leur chair. Au moins huit dépêches différentes, toutes datées de 1933, relatent des cas de cannibalisme ou d'anthropophagie (p. 144, 165, 177, 185, 196, 208, 211, 213-214). Tout en demeurant sobres et factuelles, ces dépêches n'en finissent pas de dépeindre et faire ressentir l'horreur et, comme l'écrit Werth, la régression, la « décivilisation » de l'humanité confrontée à une famine et une politique aussi cruelles.

\section{NOTES}

1. Andrea Graziosi, « "Lettres de Kharkov”, La famine en Ukraine et dans le Caucase du Nord à travers les rapports des diplomates italiens ", Cahiers du Monde russe et soviétique, 30 (1-2), janvier-juin 1989, p. 5-106.

2. James E. Mace, Communism and the Dilemmas of National Liberation : National Communism in Soviet Ukraine, 1918-1933, Cambridge, MA, 1933 ; id., " Famine and Nationalism in Soviet Ukraine ", Problems of Communism, 33, mai-juin 1984, p. 37-50; Robert Conquest, The Harvest of Sorrow : Soviet Collectivization and the Terror-Famine, Oxford University Press, 1986.

\section{AUTEURS}

\section{LUCIEN BIANCO}

EHESS 